\title{
Rheumatic manifestations of hematologic malignancies: Correlation with laboratory markers
}

\author{
Shereen R Kamel ${ }^{1}$, Ahmed M Abdel-Nasser ${ }^{1}$, Mervat M Mohamed ${ }^{2}$ \\ 1. Rheumatology \& Rehabilitation. 2. Radiation Oncology departments, Faculty of Medicine, Minia University, Egypt. \\ Correspondence: Shereen R Kamel. Address: Rheumatology and Rehabilitation department, Minia University, Egypt. \\ Telephone: 20-016-5800-025. Email: sh_rr70@yahoo.co
}

Received: October 29, 2011

Accepted: November 13, 2011 Published: December 1, 2011

DOI : $10.5430 /$ jhm.v1n1p15

URL: http://dx.doi.org/10.5430/jhm.v1n1p15

\begin{abstract}
Objective: To determine the rheumatic manifestations associated with hematologic malignancies namely acute and chronic leukemia, Hodgkin's and non-Hodgkin's lymphomas, and multiple myeloma; and the markers correlating with their presence.

Methods: Eighty patients with hematologic malignancies (28 leukemia, 28 lymphoma and 24 multiple myelomas) were evaluated and examined for the presence of rheumatic manifestations, clinically, radiologically, and by bone scan. Two groups of controls: clinical and laboratory ( 80 and 15 healthy individuals from the normal population respectively) were also studied. Routine laboratory tests and bone marrow aspiration were done for all patients, while serum rheumatoid factor (RF), antinuclear antibodies (ANA), creatine phosphokinase (CPK), and serum beta-2 macroglobulin were assessed as a marker for rheumatic manifestations in patients and controls.
\end{abstract}

Results: Rheumatic manifestations were identified in 50 patients with hematologic malignancies (62.5\%) and 21 clinical controls $(26.3 \%)(p<0.001$, odds ratio=4.7, and 95\% confidence interval=2.4-9.2). Arthralgia and low back pain were the most significantly rheumatic manifestations associated with hematological malignancies in comparison with healthy controls ( $\mathrm{OR}=15.4$, and $\mathrm{OR}=3.4$ respectively). Serum beta- 2 macroglobulin was elevated in 38 patients (47.5\%), rheumatoid factor was positive in 30 patients (37.5\%), and ANA was found in $19(23.7 \%)$ with a significant difference between patients and laboratory controls. 60 patients (75\%) had radiological findings and 19 patients (23.75\%) had an increased uptake in bone scan. Serum beta-2 macroglobulin was positively correlated with rheumatic manifestations $(r=0.21, p=0.02)$, osteopenia in $x$-rays $(r=0.24, p=0.03)$, and increased uptake in bone scan $(r=0.41, p<0.001)$.

Conclusion: Rheumatic manifestations occur in $62.5 \%$ of patients with leukemia, lymphoma, and myeloma, significantly more commonly than in age and sex-matched controls. They may precede the other manifestations of malignancy (31.3\%), occur during the course of illness (25\%) or follow as a complication of chemotherapy (6.3\%). Serum beta-2 macroglobulin is a useful laboratory test, being a marker for the presence of rheumatic manifestations and predicting osteopenia in $\mathrm{x}$-rays and increased uptake in bone scan. 


\section{Key words}

Rheumatic manifestations, Leukemia, Lymphomas, Myeloma, Laboratory markers

\section{I ntroduction}

Hematologic malignancies are types of carcinoma that affect blood, bone marrow and lymph nodes. They include leukemia, lymphomas (Non-Hodgkin's Lymphoma), Hodgkin's disease (which is also called Hodgkin's Lymphoma) and myeloma $[1,2]$.

Hematologic malignancies have been associated with a variety of rheumatic and multisystemic manifestations. The clinical features may be due to primary or metastatic involvement of the musculoskeletal system, paraneoplastic disease, or immune system dysregulation [3].

Leukemia is a very common and serious cancer that starts in blood-forming tissues, and it can be chronic or acute [4]. $13.5 \%$ of patients overall have articular symptoms as presenting features of leukemia [5]. Leukemic arthritis usually polyarticular, migratory or additive, joint pain disproportionate to degree of arthritis, possible positive rheumatoid factor, rheumatoid-like nodules have been reported, and most commonly affecting knees and ankles [6]. Bone, joint pain, and back pain sometimes occur [7]. The common radiographic findings in adults are osteopenia and osteolytic lesions, whereas osteosclerosis, osteolytic lesions, osteopenia, cortical and periosteal lesions, and metaphyseal radiolucent bands are common in children [8].

Arthritis occurs infrequently in the lymphomas. Nonetheless, it may be the presenting feature of disease and appears to be more common in non-Hodgkin's lymphoma (versus Hodgkin's disease) [3]. Monoarticular arthritis may involve the knee and present as a popliteal mass [9]. Polyarticular presentations may mimic RA, rheumatic fever, and adult-onset Still's disease [10]. Sacrioiliitis, enthesopathies and carpal tunnel syndrome sometimes occur [11,12].

Multiple myeloma is commonly affects the skeletal system. Pathologic fractures are common in patients with diagnosed and undiagnosed disease [13]. Inflammatory arthritis has rarely been reported in multiple myeloma. Symmetric polyarticular synovitis may mimic rheumatoid arthritis in some patients. Rheumatoid factor and antinuclear antibodies are usually absent. Oligoarticular arthritis may be confused with spondyloarthropathies [14].

The aim of this study was to determine the rheumatic manifestations associated with hematologic malignancies namely acute and chronic leukemia, malignant lymphoma and multiple myeloma; and the markers correlating with their presence.

\section{Patients and methods}

\section{Study population}

Eighty patients with hematologic malignancies (28 leukemia, 28 lymphoma and 24 multiple myeloma) were consecutively recruited from Minia Oncology Center at Minia governorate, Egypt. They were 47 males and 33 females, their age ranged from 3-79 years with mean $35.2 \pm 20.1$ years, and disease duration ranged from 1 week-7 years with mean $1.4 \pm 1.6$ months.

All patients were diagnosed and classified according to clinical, laboratory, bone marrow aspirate and histopathological examination.

Informed consent was obtained from the patients or their legal guardians to be included in the study. 
Exclusion criteria were the preexisting rheumatic diseases (Still's disease, rheumatoid arthritis, rheumatic fever, gout, systemic lupus erythematosus, inflammatory muscle disease); preexisting systemic diseases (diabetes, renal disease, liver disease, thyroid disease); and hepatitis $\mathrm{C}$ virus infection.

Two groups of age and sex matched controls were included in the study. The first group (clinical controls) included 80 healthy individuals (47 males and 33 females) who were examined for rheumatic manifestations, their age ranged from 3-79 years with mean $32.9 \pm 18.56$ years. The second group (laboratory controls) included 15 healthy individuals ( 9 males and 6 females) to determine normal ranges of laboratory parameters, their age ranged from 15-50 years with mean $34.2 \pm 11.2$ years.

\section{Clinical evaluation}

All the patients were subjected to a thorough history taking, general examination, and rheumatological examination.

\section{Laboratory studies}

Complete blood count, erythrocyte sedimentation rate(ESR), liver and kidney function tests, serum uric acid, serum calcium, lactic dehydrogenase (LDH), complete urine analysis, and bone marrow aspiration were done for all patients. Immunoelectrophoresis and protein electrophoresis were done for patients with multiple myeloma, immunocytochemistry was done for patients with leukemia and lymphoma, and lymph node biopsy was done for patients with lymphoma and some cases of multiple myeloma.

Sera from all patients and laboratory controls were tested for rheumatoid factor (RF) by Latex fixation test, antinuclear antibodies (ANA) by ELISA, creatine phosphokinase (CPK) by photometry, and Serum $\beta-2$ microglobulin by ELISA.

\section{I maging studies}

All patients were assessed by skeletal surveys, and conventional Tc-99m MDP bone scanning.

\section{Statistical analysis}

The statistical analysis was performed using SPSS 11.0. The chi-square test was used for an overall approach to compare percentages among the groups. ANOVA test compare the difference between more than two group means in interval and ordinal variables. Risk estimate was done by odds ratio. Correlations were calculated using Pearson Product Moment correlation. The level of statistical significance was set at a $p<0.05$.

\section{Results}

\section{Patients' characteristics}

The studied patients were classified into three groups:

Group I, included 28 patients with leukemia (13 acute lymphoblastic leukemia "ALL", 3 acute myelocytic leukemia "AML", 2 chronic lymphoblastic leukemia "CLL", and 10 chronic myelocytic leukemia "CML"), their age ranged from 3-65 years and their disease duration ranged from 0.02-6 years.

Group II, included 28 patients with lymphoma (18 Non-Hodgkin's lymphoma "NHL", and 10 Hodgkin's lymphoma "HL"), their age ranged from 12-61 years; and their disease duration ranged from 0.1-5 years. 
Group III, included 24 patients with multiple myeloma "MM", their age ranged from 33-79 years; and their disease duration ranged from 0.08-7 years.

\section{Prevalence of rheumatic manifestations}

Among eighty patients with hematologic malignancies, fifty patients $(62.5 \%)$ had rheumatic manifestations: Nineteen patients with leukemia (38\%) (9 ALL, 2 AML, 1 CLL, and 7 CML), 11 patients with lymphoma (22\%) (8 NHL, and 3 HL), and 20 patients with multiple myeloma (40\%), while the rheumatic manifestations were present in 21 cases $(26.3 \%)$ of clinical controls with statistically significant difference $(p<0.001)$ as shown in table 1 .

Patients with hematologic malignancies have significant higher risk for developing rheumatic manifestations versus controls $(\mathrm{OR}=4.7)$. Arthralgia and low back pain were the most significantly rheumatic manifestations associated with hematological malignancies in comparison with healthy controls $(\mathrm{OR}=15.4$, and $\mathrm{OR}=3.4$ respectively). Enthesopathy, osteoarthritis, and carpal tunnel syndrome were not significantly different between patients and controls (table 1).

The difference of rheumatic manifestations between three groups of patients was statistically significant for bone pain $(p=0.02)$, and back pain $(p<0.001)$ (table 2$)$.

The rheumatic manifestations detected either preceded (31.3\%) or occurred during the course of illness $(25 \%)$ or as a complication of chemotherapy (5\%).

\section{Laboratory findings}

Among eighty patients with hematologic malignancies, serum beta- 2 macroglobulin was elevated in 38 patients (47.5\%), rheumatoid factor was positive in 30 patients (37.5\%), and ANA was found in 19 (23.7\%) with a significant difference between patients and laboratory controls as shown in table 3 .

\section{Radiological findings}

By skeletal survey, 60 patients (75\%) had radiological findings (23 with myeloma, 20 with leukemia, and 17 with lymphoma). The commonest findings were osteopenia (58.8\%), osteolytic lesions (22.5\%), wedged vertebra (10\%), and pathological fractures (7.5\%). The difference of radiological findings between three groups of patients was significant for osteopenia $(p=0.02)$, pathological fractures $(p=0.001)$, wedged vertebrae $(p=0.001)$, and osteolytic lesions $(p<0.001)$ (table 4).

\section{Scintigraphic findings}

By bone scan, 19 patients (23.75\%) had increased uptake (12 with myeloma, 5 with leukemia, and 2 with lymphoma), with a significant difference between three groups of patients $(p=0.001)$ (table 5$)$.

\section{Correlations between rheumatic manifestations and Laboratory markers}

A positive correlation was found between rheumatic manifestations and serum beta- 2 macroglobulin $(r=0.21, p=0.02)$, while there is no correlation with other laboratory markers. Correlations between serum beta-2 macroglobulin and Radiological / Scintigraphic findings

Serum beta- 2 macroglobulin was positively correlated with osteopenia in $x$-rays $(r=0.24, p=0.03)$, and increased uptake in bone scan $(r=0.41, p<0.001)$. 
Table 1. Prevalence, types and risk estimation of rheumatic manifestations in patients with hematologic malignancies versus clinical controls

\begin{tabular}{llllllll}
\hline Group & $\begin{array}{l}\text { Patients } \\
(\mathbf{n = 8 0})\end{array}$ & $\begin{array}{l}\text { Clinical } \\
\text { controls } \\
(\mathbf{n = 8 0})\end{array}$ & $\chi^{2}$ & $\boldsymbol{p}$ & $\begin{array}{l}\text { Odds ratio } \\
\text { (OR) }\end{array}$ & $\begin{array}{l}\text { 95\% confidence } \\
\text { interval(CI) }\end{array}$ \\
\hline $\begin{array}{l}\text { Rheumatic } \\
\text { manifestations }\end{array}$ & $50(62.5 \%)$ & $21(26.2 \%)$ & 21.29 & $<0.001^{*}$ & 4.7 & $2.4-9.2$ \\
Arthritis & $6(7.5 \%)$ & 0 & 6.23 & $0.01^{*}$ & - & - \\
Arthralgia & $30(37.5 \%)$ & $3(3.8 \%)$ & 27.83 & $<0.001^{*}$ & 15.4 & $4.5-53.2$ \\
Bone pain & $35(43.8 \%)$ & 0 & 44.80 & $<0.001^{*}$ & - & - \\
Back pain & $26(32.5 \%)$ & $10(12.5 \%)$ & 9.18 & $0.002^{*}$ & 3.4 & $1.5-7.6$ \\
Sacroiliitis & $2(2.5 \%)$ & 0 & 2.02 & 0.15 & - & - \\
Enthesopathy & $1(1.3 \%)$ & $1(1.3 \%)$ & 0 & 1.00 & 1.0 & $0.1-16.3$ \\
Osteoarthritis & $9(11.2 \%)$ & $8(10 \%)$ & 0.07 & 0.80 & 0.6 & $0.9-1.6$ \\
OA knees & 3 & 3 & & & & \\
Cervical spondylosis & 3 & 3 & & & & \\
Lumbar spondylosis & 5 & 3 & & & & - \\
Carpal tunnel & $6(7.5 \%)$ & $3(3.8 \%)$ & 1.06 & 0.30 & 0.7 & $0.2-2.2$ \\
syndrome & & & & & & - \\
Motor neuropathy & $1(1.3 \%)$ & 0 & 1.01 & 0.32 & - & - \\
Cranial neuropathy & 2 & 0 & 2.02 & 0.36 & - & - \\
Sensory neuropathy & $2(2.5 \%)$ & 0 & 2.02 & 0.15 & - & - \\
Radiculopathy & $1(1.3 \%)$ & 0 & 1.01 & 0.32 & - & - \\
\hline Sign & & & & & & - \\
\hline
\end{tabular}

* Significant $P<0.05$

Table 2. Differences between patients with leukemia, lymphoma and myeloma in frequency and types of rheumatic manifestations

\begin{tabular}{llllll}
\hline Group & $\begin{array}{l}\text { Leukemia } \\
(\mathbf{n}=\mathbf{2 8})\end{array}$ & $\begin{array}{l}\text { Lymphoma } \\
(\mathbf{n = 2 8 )}\end{array}$ & $\begin{array}{l}\text { Myeloma } \\
(\mathbf{n = 2 4 )}\end{array}$ & $\chi^{2}$ & $\boldsymbol{p}$ \\
\hline Rheumatic manifestations & $19(67.8 \%)$ & $11(39.3 \%)$ & $20(83.3 \%)$ & 11.22 & $0.004^{*}$ \\
Arthritis & $4(14.3 \%)$ & $1(3.6 \%)$ & $1(4.2 \%)$ & 2.87 & 0.24 \\
Arthralgia & $15(53.6 \%)$ & $7(25 \%)$ & $8(33.3 \%)$ & 5.13 & 0.08 \\
Bone pain & $11(39.3 \%)$ & $8(28.6 \%)$ & $16(66.7 \%)$ & 7.97 & $0.02^{*}$ \\
Back pain & $5(17.9 \%)$ & $5(17.9 \%)$ & $16(66.7 \%)$ & 18.24 & $<0.001^{*}$ \\
Sacroiliitis & 0 & $2(7.1 \%)$ & 0 & 3.81 & 0.15 \\
Enthesopathy & $1(3.6 \%)$ & 0 & 0 & 1.88 & 0.39 \\
Osteoarthritis & $3(10.7 \%)$ & $2(7.1 \%)$ & $4(16.7 \%)$ & 1.19 & 0.55 \\
Carpal tunnel syndrome & $1(3.6 \%)$ & $1(3.6 \%)$ & $4(16.7 \%)$ & 4.15 & 0.12 \\
Motor neuropathy & 0 & 0 & $1(4.2 \%)$ & 2.36 & 0.31 \\
Cranial neuropathy & $1(3.6 \%)$ & 0 & $1(4.2 \%)$ & - & - \\
Sensory neuropathy & $1(3.6 \%)$ & $1(3.6 \%)$ & 0 & 0.88 & 0.64 \\
Radiculopathy & 0 & 0 & $1(4.2 \%)$ & 2.36 & 0.31 \\
\hline * Significant $p<0.05$ & & & & &
\end{tabular}


Table 3. Laboratory investigations in patients and laboratory controls

\begin{tabular}{lllll}
\hline Group & $\begin{array}{l}\text { Patients } \\
(\mathbf{n}=\mathbf{8 0})\end{array}$ & $\begin{array}{l}\text { Laboratory } \\
\text { controls } \\
(\mathbf{n}=\mathbf{1 5})\end{array}$ & $\chi^{2}$ & $\boldsymbol{p}$ \\
\hline Increased CPK & 0 & 0 & - & - \\
Elevated B2 macroglobulin & $38(47.5 \%)$ & 0 & 11.87 & $0.001^{*}$ \\
Positive ANA & $19(23.7 \%)$ & 0 & 4.45 & $0.04^{*}$ \\
Positive RF & $30(37.5 \%)$ & 0 & 8.22 & $0.002^{*}$ \\
\hline
\end{tabular}

Table 4. Radiological findings in patients with leukemia, lymphoma and myeloma

\begin{tabular}{|c|c|c|c|c|c|c|}
\hline Group & $\begin{array}{l}\text { Leukemia } \\
(\mathrm{n}=28)\end{array}$ & $\begin{array}{l}\text { Lymphoma } \\
(\mathrm{n}=28)\end{array}$ & $\begin{array}{l}\text { Myeloma } \\
(\mathrm{n}=24)\end{array}$ & $\begin{array}{l}\text { Total } \\
(n=80)\end{array}$ & $\chi^{2}$ & $p$ \\
\hline Radiological findings & $20(71.4 \%)$ & $17(60.7 \%)$ & $23(95.8 \%)$ & $60(75 \%)$ & 8.79 & $0.01 *$ \\
\hline Osteopenia & $18(64.3 \%)$ & $11(39.3 \%)$ & $18(75 \%)$ & $47(58.8 \%)$ & 7.35 & $0.02 *$ \\
\hline Soft tissue swelling & 0 & $1(3.6 \%)$ & $1(4.2 \%)$ & $2(2.5 \%)$ & 1.12 & 0.57 \\
\hline Cysts & $1(3.6 \%)$ & 0 & $1(4.2 \%)$ & $2(2.5 \%)$ & 1.12 & 0.57 \\
\hline Erosions & $1(3.6 \%)$ & 0 & 0 & $1(1.3 \%)$ & 1.88 & 0.39 \\
\hline Sacroiliitis & 0 & $2(7.1 \%)$ & 0 & $2(2.5 \%)$ & 3.81 & 0.43 \\
\hline Enthesopathy & 0 & $1(3.6 \%)$ & $1(4.2 \%)$ & $2(2.5 \%)$ & 1.12 & 0.57 \\
\hline Avascular necrosis & $1(3.6 \%)$ & 0 & 0 & $1(1.3 \%)$ & 1.88 & 0.39 \\
\hline Osteolytic lesions & $2(7.1 \%)$ & 0 & $16(66.7 \%)$ & $18(22.5 \%)$ & 38.76 & $<0.001 *$ \\
\hline Pathological fracture & 0 & 0 & $6(25 \%)$ & $6(7.5 \%)$ & 15.13 & $0.001 *$ \\
\hline Periostitis & $1(3.6 \%)$ & $1(3.6 \%)$ & $1(4.2 \%)$ & $3(3.8 \%)$ & 0.02 & 0.99 \\
\hline Metaphyseal band & $3(10.7 \%)$ & 0 & 0 & $3(3.8 \%)$ & 5.79 & 0.05 \\
\hline Wedged vertebra & $1(3.6 \%)$ & 0 & $7(29.2 \%)$ & $8(10 \%)$ & 14.19 & $0.001 *$ \\
\hline Sclerosis & 0 & $1(3.6 \%)$ & $1(4.2 \%)$ & $2(2.5 \%)$ & 1.12 & 0.57 \\
\hline Cortical expansion & 0 & $1(3.6 \%)$ & 0 & $1(1.3 \%)$ & 1.88 & 0.39 \\
\hline \multicolumn{7}{|l|}{ Chest x-ray: } \\
\hline Pleural effusion & $1(3.6 \%)$ & $1(3.6 \%)$ & $1(4.2 \%)$ & $3(3.8 \%)$ & & \\
\hline Mediastinal mass & $1(3.6 \%)$ & $3(10.7 \%)$ & 0 & $4(5 \%)$ & 6.77 & 0.56 \\
\hline Nodular lesions & 0 & $1(3.6 \%)$ & $1(4.2 \%)$ & $2(2.5 \%)$ & & \\
\hline Bony lesions & 0 & 0 & $1(4.2 \%)$ & $1(1.3 \%)$ & & \\
\hline
\end{tabular}

* Significant $p<0.05$

Table 5. Bone scan findings in patients with leukemia, lymphoma and myeloma

\begin{tabular}{lllllll}
\hline Group & $\begin{array}{l}\text { Leukemia } \\
(\mathbf{n = 2 8 )}\end{array}$ & $\begin{array}{l}\text { Lymphoma } \\
(\mathbf{n = 2 8 )}\end{array}$ & $\begin{array}{l}\text { Myeloma } \\
(\mathbf{n = 2 4 )}\end{array}$ & $\begin{array}{l}\text { Total } \\
(\mathbf{n = 8 0}\end{array}$ & $\chi^{\mathbf{2}}$ & $\boldsymbol{p}$ \\
\hline Normal & $23(82.1 \%)$ & $26(92.9 \%)$ & $12(50 \%)$ & $61(76.3 \%)$ & & \\
Increased uptake & $5(17.9 \%)$ & $2(7.1 \%)$ & $12(50 \%)$ & $19(23.8 \%)$ & 13.93 & $0.001^{*}$ \\
\hline
\end{tabular}

*Significant $p<0.05$ 


\section{Discussion}

Rheumatic signs and symptoms may be the presenting manifestations of the underlying hematologic disease. The clinical findings may mimic those of primary rheumatologic syndromes such as rheumatoid arthritis (RA), systemic lupus erythematosus (SLE), scleroderma, or systemic vasculitis [3].

In this work, the rheumatic manifestations were found in $50(62.5 \%)$ of 80 patients with hematologic malignancies. They included: bone pain (43.8\%), arthralgia (37.5\%), back pain (32.5\%), osteoarthritis (11.2\%), arthritis (7.5\%), carpal tunnel syndrome (7.5\%), sacroiliitis $(2.5 \%)$, and enthesopathy $(1.3 \%)$.

The majority of previous studies examining rheumatic manifestations in hematologic malignancies were uncontrolled and concentrated on major rheumatic illness such as rheumatoid arthritis, lupus, dermatomyositis and vasculitis [3, 1519]. For example, Hamidou et al. [20] have studied the prevalence of rheumatic manifestations in 200 patients with hematological malignancies divided into two groups, myelodysplastic syndromes and lymphoid malignancies. Rheumatic manifestations were found in $18 \%$ of patients in the first group and $5 \%$ of the second group. Much lower prevalence of rheumatic manifestations found in this study in comparison to ours is probably due to under recording of rheumatic manifestations. Since no plain X-ray or bone scan were made for patients. The study evaluated the prevalence of antineutrophil cytoplasmic antibodies (ANCA) and examined major vasculitic and rheumatic syndromes without reporting manifestations as joint pain, bone pain and low back pain.

In agreement with our results, Mohammed [21] has reported the prevalence of rheumatic manifestations in 25 cases with leukemia and 25 cases with lymphoma. The rheumatic manifestations were found in 17 cases with leukemia (68\%): 2 of them had rheumatoid like manifestations, 3 had polyarthritis, 3 had osteoarthritis knees, 3 had fasciitis, 3 had back pain, and 4 had fibromyalgia.

Considering the leukemia patients group in this work, 19 of 28 patients $(67.8 \%)$ were encountered with rheumatic manifestations: Fifteen had joint pain (8 ALL, 1 AML, 1 CLL, 5 CML), 11 had bone pain (5 ALL, 1 CLL, 5 CML) well localized in children and diffuse in adult, 5 had back pain (1 ALL, 4 CML), 4 had inflammatory arthritis (2 ALL, 1 CLL, $1 \mathrm{CML}$ ) involved knees and ankles, 3 had osteoarthritis (1 CLL, 2 CML), 1 had enthesopathy (CML), 1 had carpal tunnel syndrome (CLL), and 1 had facial palsy (AML).

To differentiate between leukemia and other childhood rheumatic disease like juvenile rheumatoid arthritis, Tsai et al. [22] stated that children with leukemic arthritis at onset of disease had less leukocytosis and a relative lymphocytosis, or they had leukopenia. The anomaly of a moderately elevated ESR in the presence of a normal or low platelet count could be due to an infiltrative process in the marrow that is inhibiting a normal megakaryocyte response [17].

Considering the lymphoma patients group in this work, 11 of 28 patients $(39.3 \%)$ were encountered with rheumatic manifestations: Eight had bone pain ( $3 \mathrm{HD}, 5 \mathrm{NHL}), 7$ had joint pain (2 HD, $5 \mathrm{NHL}$ ), 5 had back pain (2 HD, $3 \mathrm{NHL}), 2$ had sacroiliitis (1 HD, $1 \mathrm{NHL}), 2$ had osteoarthritis (1 HD, $1 \mathrm{NHL}), 1$ had none-inflammatory arthritis (NHL) affecting proximal interphalangeal joints "but it is difficult to determine if the arthritis resulted from the disease itself or from chemotherapy", 1 had carpal tunnel syndrome (NHL), and 1 had sensory neuropathy (NHL).

In the present study, most of patients with myeloma had rheumatic manifestations (83.3\%), bone and back pain were the commonest (16 out of 24 patients). Eight patients had arthralgia, 4 had osteoarthritis, 4 had carpal tunnel syndrome, 1 had inflammatory arthritis of the knee joints, 1 had motor neuropathy, 1 had cranial neuropathy, and 1 had radiculopathy.

Among eighty patients with hematologic malignancies in this study, there were 20 cases $(25 \%)$ had paraesthesia, headache, oligoarthritis, arthralgia, bone pain, and back pain as a complications of chemotherapy. 
We did not find cases with septic arthritis, dermatomyositis, lupus-like syndrome, polymyalgia-like syndrome, vasculitis, and hypertrophic pulmonary osteoarthropathy in three groups of patients. These manifestations have been reported in previous studies with hematologic malignancies [23-27], mostly as case reports indicating its rare occurrence.

Abu-Shakra et al. [19] reported that, a high proportion of the sera of patients with hematologic malignancies binds a large number of autoantibodies. Sera of patients with multiple myeloma and chronic lymphocytic leukemia have rheumatoid factor activity and bind DNA, myelin associated glycoproteins, and other autoantigens. At the current study, the presence of rheumatoid factor and antinuclear antibodies have been related to the malignancy, not to the rheumatic manifestations and they do not help in differentiation between patients with rheumatic manifestations and those without rheumatic manifestations, also they may be misleading, resulting in misdiagnosis of malignancy.

Kyle (1995) reported that the serum beta-2 macroglobulin concentration is elevated in a wide variety of malignancies and inflammatory conditions, and this coincides with our results as the serum beta- 2 macroglobulin was elevated in 38 patients (47.5\%) (Sixteen patients with leukemia, 12 patients with lymphoma, and 10 patients with myeloma).

In the present study, serum beta-2 macroglobulin was positively correlated with rheumatic manifestations as a whole $(r=0.21, p=0.02)$, osteopenia in X-rays $(r=0.24, p=0.03)$, and increased uptake in bone scan $(r=0.41, p<0.001)$. However, none of the previous studies mentioned these results. Therefore, beta- 2 macroglobulin can be considered as an important marker for the presence of rheumatic and/or radiological manifestations in patients with hematologic malignancies.

In conclusion, rheumatic manifestations occur in $62.5 \%$ of patients with hematologic malignancies, significantly more commonly than in age- and sex-matched controls, with an odds ratio of 4.7. Joint pain, bone pain, low back pain and arthritis are the commonest manifestations. Awareness of these rheumatic manifestations is of great importance as some of them may be helpful in early detection of the malignant disease. RF and ANA are not useful diagnostic tests for evaluating those patients, being falsely positive and not discriminating patients with and without rheumatic manifestations. Beta-2 macroglobulin is a useful laboratory test, being a marker for the presence of rheumatic manifestations and predicting osteopenia in $\mathrm{x}$-rays and increased uptake in bone scan. Therefore, the relationship between beta- 2 macroglobulin and the presence of rheumatic manifestations and/or radiological findings needs further evaluation.

Further investigation into the association between rheumatic manifestations and hematologic malignancies, their markers and determinants is also recommended in larger series.

\section{Conflict of interest}

The authors have no conflicts of interest to declare.

\section{References}

[1] Ge X, Wang X. Role of Wnt canonical pathway in hematological malignancies. J Hematol Oncol. 2010 Sep 15;3:33. http://dx.doi.org/10.1186/1756-8722-3-33

[2] Hammerschmidt D, Peterson BA. Blood, bone marrow and lymphatic cancers (Hematologic malignancies). Cancer 2001 Oct 17.

[3] Duna GF, Cash JM. Rheumatic manifestations of dysproteinemias and lymphoproliferative disorders. Clinical Immunology and the Rheumatologist. 1996;22(1):39-51.

[4] Torkaman A, Charkari NM, Aghaeipour M. An approach for leukemia classification based on cooperative game theory. Anal Cell Pathol (Amst). 2011 Aug 12. [Epub ahead of print].

[5] Holdrinet RS, Corstens F, Van Horn JR, et al. Leukemic synovitis. Am J Med. 1989;86:123-26. http://dx.doi.org/10.1016/0002-9343(89)90244-1

[6] Valeriano J. Malignancy and rheumatic disease. Cancer Control Journal. 1997;4(3). 
[7] Beers MH, Berkow R (eds). Hematological malignancies. In: Merck Manual of diagnosis and therapy. 17 th, 1997.

[8] Mody GM, Cassim B. Rheumatologic features of hematologic disorders. Current Opinion in Rheumatology. 1996;8:57-61. PMid: 8867541. http://dx.doi.org/10.1097/00002281-199601000-00011

[9] Haase KK, Dürk H, Baumbach A, et al. Non-Hodgkin's lymphoma presenting as knee monoarthritis with a popliteal cyst. J Rheumatol. 1990;17:9.

[10] McDonagh JE, Clarke F, Smith SR, et al. Non-Hodgkin's lymphoma presenting as polyarthritis. Br J Rheumatol. 1994;33:79. http://dx.doi.org/10.1093/rheumatology/33.1.79

[11] Cohen MR, Carrera GE, Lundberg J. Rapidly progressive sacroiliitis in a patient with lymphocytic lymphoma. Ann Rheum Dis 1993;52:239-40. PMid: 8484681. http://dx.doi.org/10.1136/ard.52.3.239

[12] Chevalier X, Hermine O, Authier FJ, et al. Carpal tunnel syndrome due to T cell lymphoma. Arthritis Rheum. 1995;11:1707-09. http://dx.doi.org/10.1002/art.1780381125

[13] Scharschmidt TJ, Lindsey JD, Becker PS, Conrad EU. Multiple myeloma: diagnosis and orthopaedic implications. J Am Acad Orthop Surg. 2011 Jul:19(7):410-19. PMid: 21724920.

[14] Hurst NP, Smith W, Henderson DR. IgG (kappa) paraproteinaemia and arthritis. Br J Rheumatol. 1987;26:142. http://dx.doi.org/10.1093/rheumatology/26.2.142

[15] Naschitz JE, Rosner I, Rozenbaum M, et al. Cancer-associated rheumatic disorders. Semin Arthritis Rheum 1995; 24(16):231-41.

[16] Kurzrock R, Cohen PR. Mucocutaneous paraneoplastic manifestations of hematologic malignancies. Am J Med. 1995;99:20716. PMid: 7625426.

[17] Cabral DA, Tucker LB. Malignancies in children who initially present with rheumatic complaints. J Pediatr. 1999;134:53-57. http://dx.doi.org/10.1016/S0022-3476(99)70372-0

[18] Ehrenfeld M, Gur H, Schoenfeld Y. Rheumatologic features of hematologic disorders. Curr Opin Rheumatol. 1999;11:62-67. PMid: 9894632. http://dx.doi.org/10.1097/00002281-199901000-00011

[19] Abu-Shakra M, Buskila D, Ehrenfeld M, et al. Cancer and autoimmunity: autoimmune and rheumatic features in patients with malignancies. Ann Rheum Dis. 2001;60:433-40. PMid: 11302861. http://dx.doi.org/10.1136/ard.60.5.433

[20] Hamidou M, Derenne S, Audrain M, et al. Prevalence of rheumatic manifestations and antineutrophil cytoplasmic antibodies in hematological malignancies. A prospective study. Rheumatology. 2000;39:417-20. PMid: 10817775.

http://dx.doi.org/10.1093/rheumatology/39.4.417

[21] Mohammed GM. Prevalence of rheumatic manifestations among patients with hematologic malignancies "leukemias and lymphomas". Thesis for M.Sc. degree, Cairo University, 2002.

[22] Tsai MJ, Yan DC, Chiang BL, et al. Childhood leukemia mimicking juvenile rheumatoid arthritis. Acta Paediatr Sinica. 1995;36:274-79.

[23] Sánchez-Guerrero J, Gutiérrez-Ureña S, Vidaller A, et al. Vasculitis as a paraneoplastic syndrome. Report of 11 cases and review of the literature. J Rheumatol. 1990;17:1458-62. PMid: 2273485.

[24] Montanaro M, Bizzarri F. Non-Hodgkin's lymphoma and subsequent acute lymphoblastic leukemia in patient with polymyalgia rheumatica: case report. Br J Rheumatol. 1992;31:277-78. http://dx.doi.org/10.1093/rheumatology/31.4.277

[25] Cuende E, Barbadillo C, Mazzucchelli RE, et al. Candida arthritis in adult patients who are not intravenous drug addicts: report of three cases and review of the literature. Semin Arhtritis Rheum. 1993;22:224-41. http://dx.doi.org/10.1016/0049-0172(93)80071-M

[26] Falcini F, Taccetti G, Bartolozzi G. Acute lymphocytic leukemia with dermatomyositis-like onset in childhood. J Rheumatol. 1993;20:1260-62. PMid: 8371239.

[27] Naschitz JE, Rosner I, Rozenbaum M, et al. Rheumatic syndromes: Clues to occult neoplasia. Semin Arthritis Rheum. 1999;29:43-55. http://dx.doi.org/10.1016/S0049-0172(99)80037-7 